\title{
The impact of monetary policy on long-run share price reversals on the Johannesburg Securities Exchange
}

\author{
Rollins NG Ayaya \\ Runxin Lin \\ Department of Business Finance \\ University of Witwatersrand, South Africa \\ Onesmus Ayaya \\ School of Accountancy, University of Limpopo \\ South Africa
}

Keywords: Share, price, reversal, monetary, policy, portfolio

\begin{abstract}
Purpose: The study expands on the phenomenon of long-run reversal in the financial markets using Johannesburg Stock Exchange (JSE) data. This study aimed to determine whether the monetary policy changes implemented by the South African Reserve Bank influence long-run reversals in the JSE.

Context: Long-run reversals have occurred in various global financial markets in the US, Europe, Asia, and South Africa. Long-run reversals occur when firms with poor past performance rebound and produce superior returns to firms with good historical past performance. South Africa has a monetary policy of inflation targeting. It tends to increase interest rates whenever the change in the consumer price index falls above the upper limit of the range of 3-6\%.

Methods: The regressions of the Fama-French three factors model and the Fama-MacBeth model were used to estimate the relationship between the excess return of different portfolio returns and the Fama-French three factors. Furthermore, we split our sample under expansive and restrictive monetary conditions. We ran the regression of the Fama-MacBeth model again to see whether the monetary conditions influence the long-run reversal.

Results: The sample results over the near 15-year sample period show that firms with poor past performance failed to outperform those with past solid performance. In addition, monetary policy changes did not lead to long-run reversals among poor performing firms. The gap is closed under restrictive monetary conditions.

Practical value: The study recommends that one could do a detailed examination of the relationship between firm characteristics and long-run reversals under various monetary conditions. Monetary conditions are worth watching for when constituting a portfolio because they create arbitrage opportunities for astute investors.
\end{abstract}

\section{Introduction}

There has been significant research on long-run stock reversals in the US and European equity markets. There is wide-ranging evidence pointing to the tendency for equity instruments to perform well in the previous six to twelve months in the subsequent six to twelve months. Garcia-Feijoo and Jensen (2014) examined reversals during two monetary environments, namely the expansionary monetary environment and the restrictive monetary environment. Monetary environments are critical to determining liquidity-related issues. Garcia-Feijoo and Jensen (2014) did an extensive study on the effect of long-run reversals for firms in the USA. They extended the research of Fama and French (1996) by 17 years to determine if reversals are still prominent in the US and the reason behind their occurrence. Dyl et al. (2019) showed that investors overreact to non-information-based price movements and underreact to public statements comprising company-specific information.

On the contrary, Blackburn and Cakici (2017) did a similar study focused primarily on developed nations within the North American, European, and Asian regions. Zaremba (2016) examined long-run reversals in 74 countries, including South Africa, but did not do extensive research on the Johannesburg 
Stock Exchange (JSE) index. Numerous studies investigated the relationship and effects that overreaction has on share prices. South African scholars, such as Page and Way (1992), Hsieh and Hodnett (2011), Muller (1999), and more recently, Britten et al. (2016), examined the overreaction theory in a South African context. They all concluded that reversals tend to occur because of overreaction. Different classes of shares (in the Chinese settings) with varying classes of clientele have been shown to have other monthly share price reversals. Institutional ownership strengthens momentum in B shares (Chui et al., 2021).

\section{Context}

South Africa has a different monetary framework than the US. These framework differences could yield different results compared to the previous US study by Garcia-Feijoo and Jensen (2014). Nominal interest is heavily dependent on the inflation rate because one needs to add both the real interest and inflation to calculate nominal interest. South Africa's monetary policy framework differences can also potentially affect the study and explain why South Africa's empirical findings are different from that of the USA. According to the South African Reserve Bank, the monetary authorities use inflation targeting to achieve their monetary policy objectives instead of other frameworks such as nominal income targeting, exchange rate targeting and nominal income targeting. The South African Reserve Bank has been using inflation targeting as a monetary policy framework since 2000. The US Federal Reserve, on the other hand, uses different tools. The US Federal Reserve's monetary policy promotes maximum employment, stable prices, and moderate long-term interest rates. The South Africa Reserve Bank pursues an inflation targeting policy that promotes stable prices. South Africa has experienced expansions and contractions of the interest rates, which can affect equity investment decisions, and ultimately, share price movements. This paper explores the effect of monetary policy changes on the reversals of loser and winner stocks in the long run.

\section{Problem statement}

There have also been studies on the phenomenon in South African markets (Britten et al., 2016; Page \& Way, 1992). However, none has considered monetary conditions. Long-run stock reversals are the tendency of firms with poor share performance to eventually outperform companies with good share performance over the past five years. Research on reversals has the limitation of not examining other effects of reversals, such as the conditional monetary effects, which this paper aims to delimit. We consider the need to factor in various monetary conditions (restrictive and expansionary) alongside different firm characteristics to examine the reason behind their reversals. Restrictive monetary policy deals with reserve bank mechanisms to slow economic growth through restricted liquidity. Firm features include firm size (measured by market capitalisation), book-to-market equity (BEME) ratio, and firms with high and low beta stocks. Most liquid and large companies were noted to have significant share price reversals (Rif \& Utz, 2021). The following question is worth asking: Are the considerable share price reversals associated with monetary policy conditions? US monetary tightening is a single global factor that explains the variation of risky asset prices worldwide (Miranda-Agrippino \& Rey, 2020). Therefore, to what extent does monetary conditions in South Africa explain the variations of share prices on the JSE?

\section{The aim of the study}

The research aimed to determine if monetary policies affect long-run reversals in South Africa. The findings would help equity investors understand the JSE market better and interface with the monetary policy regime. It would also help finance professionals to take advantage of the potential arbitrage opportunities at hand if the long-run reversals are a phenomenon in the JSE. This article explores the transmission of monetary policy through monetary conditions (within financial intermediation) and prices, an area that has not been sufficiently covered using South African data.

\section{Literature survey}

Past scholars noticed the long-run reversal effects over the past few decades in various equity markets worldwide. The literature offers multiple explanations for the observed pricing trends following price movements. The reasons fall within the liquidity, overreaction, and underreaction postulates. There 
have been intensive studies focused primarily on US markets, and more recently, Asian, and European markets. Key authors include De Bondt and Thaler (1985), Fama and French (1996), Garcia-Feijoo and Jensen (2014) and Britten et al. (2016). One of the main reasons behind the reversals is overreaction (De Bondt \& Thaler, 1985) in which equity investors attach significant importance to current information. However, according to Garcia-Feijoo and Jensen (2014, p. 4), one of the explanations behind these longrun reversal patterns is rational, economic investor behaviour. Garcia-Feijoo and Jensen (2014, p. 4) argue that "stock return expectations are affected by time variation in the funding conditions for investors and firms". Garcia-Feijoo and Jensen (2014) primarily investigated the relationship between monetary conditions and long-term reversals in stock prices for winner and loser stocks in the US markets. In South Africa, Britten et al. (2016) examined the overreaction hypothesis in which equity investors overweigh current events and under weigh historical information. The alternative explanations to the share price reversals are discussed in this section.

\section{Overreaction theory}

De Bondt and Thaler $(1985,1987)$ are leading, critical authors who examined overreaction in equity markets. They used equally weighted monthly return data from the New York Stock Exchange (NYSE) between 1926 and 1982. They concluded that shares with a prolonged period of poor performance in US markets somehow outperformed winners by an average of 31,9\% over the next five years. They stated that this was due to overreaction. Investors tend to become overly pessimistic about stocks that perform poorly and excessively optimistic about stocks that exhibit superior performance. South African researchers Page and Way (1992) looked at the stock market reaction from a South African perspective and found that stock markets show overreaction. They believed that overreaction behaviour is due to investors paying too much attention to recent dramatic news. In Page and Way's (1992) study, the prior 'losers' portfolios on average outperformed the 'winners' by about $20 \%$ over the three years after portfolio formation. Their results were consistent with the overreaction hypothesis, which predicts that traders tend to overreact to unexpected and dramatic news events, whether it is good or bad news. Page and Way (1992) believed that the findings suggested a substantial weak form of inefficiency in the South African stock market over the long-term horizon.

Muller (1999) also examined overreactions in South Africa and acknowledged that the JSE is no exception to weak-form inefficiencies. They concluded that investor overreaction in the JSE was evident. The loser portfolios of the study yielded higher excess market returns, while the winner portfolios yielded lower excess market returns with an increased holding period. This raises the following question: Does the information used by the investors include liquidity information?

Hsieh and Hodnett's (2011) study extended Page and Way's (1992) research in the JSE markets. Their empirical results agreed that overreaction of stock prices was present. However, the overreaction hypothesis contradicted the efficient market hypothesis in South Africa. Weak form efficient market hypothesis states that investors cannot consistently outperform the market using historical price patterns (De Bondt \& Thaler, 1985). It is believed that investor overreaction systematically causes market prices to overshoot (De Bondt \& Thaler, 1985). The reversals of share prices should thus be predictable to provide arbitrage investment opportunities, hence the argument by Hsieh and Hodnett (2011) that the overreaction hypothesis directly contradicts the efficient market hypothesis. The period covered by the De Bondt and Thaler's (1985) study relates to the period affected by economic sanctions against the apartheid regime.

Blackburn and Cakici (2017) examined overreaction in 23 developed countries, including North America, Europe, Japan, and Asia. Despite Japan being geographically located in Asia, it was categorised because of its heavy market-capitalisation presence. The European countries consisted of Germany, the UK, Portugal, and Austria; the Asian countries included Singapore, Hong Kong, New Zealand, and Australia. In an equally weighted portfolio, the long-run reversals were present and statistically significant for North America, Japan, and Asia yet insignificant for Europe. The strategy longing winners and shorting losers in the long-term would yield a statistically significant average monthly return on -80 basis points over the sample period in North America. This suggested that the reversal phenomenon is due to 
making a loss from longing the winner portfolio. Japan and Asia yielded similar results. We submit that the use of monthly return data should have been affected by monetary conditions, which we look at next. The studies reviewed did not consider different forms of shares and their clientele classes.

\section{Monetary conditions}

Bjørnland and Leitemo (2009) reported a considerable simultaneous interaction between the interest rates and shocks to share prices in the US. Garcia-Feijoo and Jensen (2014) supported this by registering returns for expansive and restrictive monetary environments from 1963 to 2010. They looked at the returns to a portfolio of stocks in the long position (loser quintile) and stocks of the short position (winner quintile). This portfolio was referenced as 'loser minus winner' (LMW). They also reported on monetary and reserve aggregates across the two aggregates.

A restrictive monetary condition exists whenever the reserve bank slows economic growth through reduced liquidity. The reserve bank lowers the amount of money and credit banks can lend by making loans, credit cards, and mortgages more expensive. Reduced liquidity should make inventors sell their portfolio holding to access cashflows. Share prices could then decline on the strength of oversupply. An expansive monetary condition is the direct opposite. It aims to increase aggregate demand and economic growth in the economy. The reserve bank cut interest rates or increase the money supply to boost economic activity. Ayaya (2002) contended that real economic growth is Granger caused by the domestic credit to the private sectors, which is affected by the monetary policy.

\section{South Africa's monetary history}

South Africa and the US have different economies, and therefore, these differences in monetary policy frameworks may affect the results of this study to show different results to Garcia-Feijoo and Jensen (2014). Monetary policy frameworks generally depend on the following three things: (i) structural differences (ii) varying degrees of indexation, and (iii) institutional arrangements and analytical constraints (Fry et al., 2000). Structural differences are a significant factor because they involve the structure of a country's financial sector, debt levels, and fiscal discipline, which differs between countries.

In the duration (1963-2010) of Garcia-Feijoo and Jensen's (2014) study, the monetary policy tools varied from maintaining fixed exchange rates post World War II to money supply targeting in the 1970s. According to the US Federal Reserve (2020) website, when the US Federal Reserve maintained a fixed exchange rate, they offered to buy or sell a unit of domestic currency for a set amount of foreign currency. A country that maintains a fixed exchange rate has the same inflation as other countries that do not. Therefore, countries with volatile or high inflation prefer to link their monetary policy, using the fixed exchange rate, to an economically robust country like the US or Germany. In the 1970s, monetary supply targeting was used. The technique used by the US Federal Reserve expands the money supply at a prespecified and fixed rate over time. This method is used to limit the chances of inflation over time. The US experienced heavy inflation in the 1970s, and thus, incorporated this technique (US Federal Reserve, 2020).

South Africa has been using inflation targeting as their monetary policy framework for the $21^{\text {st }}$ century. Inflation targeting is a central banking strategy of setting an inflation rate goal and adjusting the monetary policy to achieve that goal. The objective of inflation targeting is maintaining price stability and supporting economic growth and stability. It has been proven by Statista (2020; Figure 1) that South Africa's inflation has experienced severe fluctuations, proving the existence of inflation targeting shown by the range of $1,43 \%$ to $10,99 \%$ between the years 2000 and 2020. Figure 2 highlights the correlation between interest rates and inflation. As inflation increases, interest rates tend to move in the same direction, proving the positive relationship between the two variables between 2000 and 2020. South Africa's inflation has proven to be a lot more volatile than that of the US. The US has been attempting to target its inflation levels at $2 \%$. 
Figure 1: South Africa's interest rate from 1984-2020

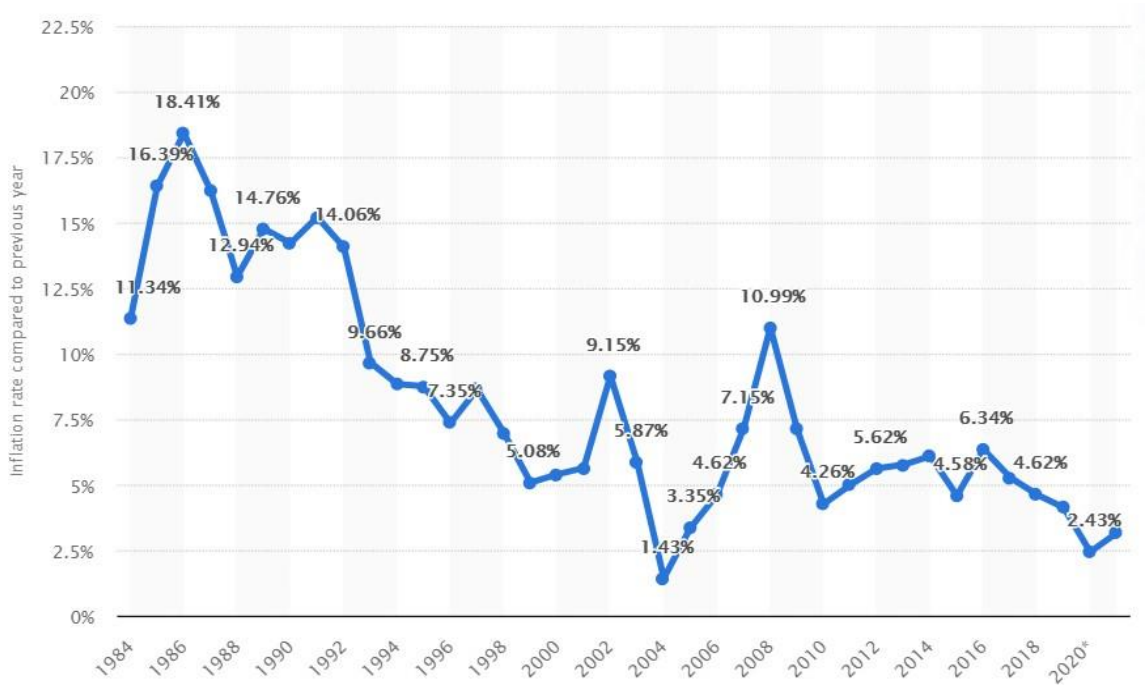

Source: Statista

Figure 2: Comparison in the relationship between South Africa's interest rate and inflation from 19962020

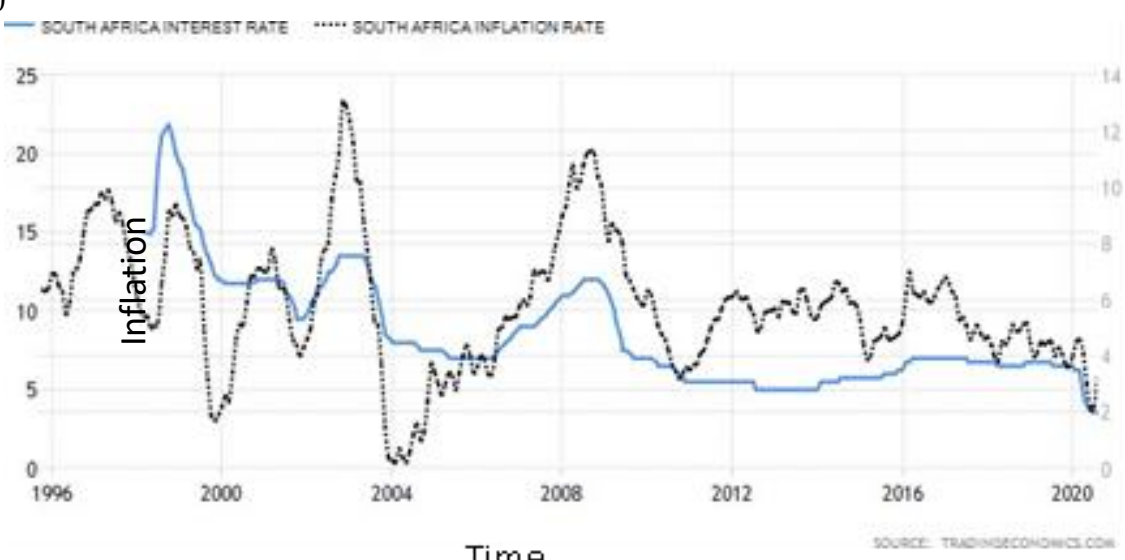

Source: Trade Economics (2020)

Firm characteristics, monetary conditions, and long-run reversals

The long-run reversal of share prices in the US also experienced effects by firm characteristics (GarciaFeijoo \& Jensen, 2014). Firm features included firm size (measured by market capitalisation), various BEME ratios, and firm betas. Garcia-Feijoo and Jensen's (2014, p. 16) research found that the monetary environment is expected to have a more "prominent influence on firms that have limited access to capital and firms that are heavily reliant on external sources of capital".

The reversal phenomenon was more definite for small firms compared to big firms. Firm size and BEME can both be viewed as a proxy for the firm's access to capital (Garcia-Feijoo \& Jensen, 2014). Bekaert and Hodrick (1992) characterise the expected elements in excess rates of returns on major equity and foreign exchange markets by employing lagged excess returns, dividend yields, and forward premiums. Fama and French (1992) suggested that firms with relatively high BEME are more frequently financially distressed than firms with relatively low BEME. They found that high-BEME firms, also known as value firms, tend to have a more significant earnings uncertainty, higher leverage, and a greater tendency to reduce their dividend. Fama and French (1992) supported this theory by reporting that BEME is a proxy for risk and the higher the BEME, the riskier the firm. Financially distressed firms face more significant 
problems when attempting to secure financing. Thus, there is more reason to expect a more major reversal for firms with high BEME ratios. Garcia-Feijoo and Jensen's (2014) findings showed that reversals are conditional on the monetary environment. They learnt that losers only reversed when monetary conditions are expansive. Meanwhile, winner reversals are commonly isolated within restrictive environments. Secondly, the reversal of loser stocks was found to be driven by the price movements of small-capitalisation stocks (small firms), high-BEME stocks (high-value firms), and stocks with high systematic risk. They found that a significant loser reversal is mainly identified when the monetary environment is expansive. Like the loser reversal (above), winner reversals are limited to stocks with small- market-cap, growth features, and high systematic risk.

\section{The anomalies on the securities exchange}

Anjum (2020) provided results of three market anomalies (day-of-the-week effect, weekend effect and monthly) using data from the Pakistan and Karachi Stock Exchanges. The research results showed that December and March mean it returns high in Karachi Stock Exchange and Pakistan Stock Exchange, respectively. The month of January is also known to significantly affect share prices on other securities exchanges. However, researchers have yet to determine why January drives superior returns.

Reversals are also seen to be frequently and significantly affected in January. De Bondt and Thaler (1987) and Grinblatt and Moskowitz (2004) reported that long-run reversals for losers are more concentrated in January. The January anomaly has been attributed to tax bases in the relevant jurisdiction. The end-of-year tax-based trading decisions may be responsible for the reversal pattern exhibited by losers. George and Hwang (2007) confirmed this theory and concluded that loser stocks' long-run reversal is exclusive to January. These systematic trends in the securities market contradict the efficient market postulates given that market returns can be predicted from known trends and not publicly available information. Arendas et al. (2021) showed that there are significant January effects on the security prices in the markets of Eastern Europe.

\section{Momentum theory}

The momentum effect refers to the inclination of equity securities that perform well in the previous half-year to a year to perform well in the subsequent half-year to a year (Chui et al., 2021). The momentum phenomenon refers to when security prices are experiencing accelerated changes and are expected to continue these changes in the future. It was found that the investor behavioural biases that cause shortterm momentum are the same that cause long-term reversals (Hong \& Stein, 1999). However, George and Hwang (2004) found that the anomalies are separate and concluded that the two return patterns are distinct phenomena and are encouraged by different investor behaviours. Chui et al. (2021) contended that these trends are in harmony with a situation where momentum is caused by informed investors who underreact to information signals and that short-term reversals denote premia to incorporate the demands of those who demand short-term liquidity. Predicting future returns from past returns can be attributed to clientele groups with different investment objectives; for instance, pension funds could contribute to momentum effects.

George and Hwang (2004) proposed two investor behavioural biases, namely anchoring and reference points, as explanations for price momentum. These authors, however, found that these behavioural biases do not explain long-run price reversals. However, according to Page et al. (2013), there is evidence of both a short-term momentum effect and the beginnings of a longer-term reversal. Page et al. (2013) reported that price momentum is present in the JSE. The authors investigated short- and medium-term momentum strategies in the JSE from January 1995 to December 2010. Page et al. (2013) reported a significant momentum effect on the JSE over the sample period, yet the magnitude of profits declined in the latter half of their sample. There is evidence of both a short-term momentum effect and the beginnings of a longer-term reversal, proving a relationship between the two. We postulate that the phenomenon observed could be associated with institutional constraints unique to the JSE. For instance, the foreign exchange controls and liquidity situation could make investors operate within different clientele groupings.

Conference proceedings of the Centre for Business \& Economic Research, ROGE-2021, 9-10 December 


\section{Description of overall research design}

The overall study design was motivated by Garcia-Feijoo and Jensen (2014) who linked the existence and stringency of long-term reversals patterns to monetary conditions. Specifically, it is essential to test whether there is a long-run share price reversals pattern in South Africa and determine whether this reversal pattern is influenced by a firm's access to financing and the monetary environment in South Africa. The study used quantitative methods to explore share price reversals while factoring in monetary policy changes. The study adapted Garcia-Feijoo and Jensen's (2014) US study to a South African context to establish whether their findings are universally acceptable. The researchers are positivists and believe that knowledge can be generated from reality and data independent of the research. Market players act on publicly available information that influences share prices.

\section{Data and methods}

\section{Sampling and data collection}

Daily data for securities listed on JSE was obtained from the Bloomberg terminal for the period January 2000 to December 2019. The period is long enough to identify loser and winner stock and to subsequently build the test portfolios. The daily data from the terminal included closing share price, price to earnings ratio, and the market capitalisation of shares. There were 458 firms in our sample.

The South African Reserve Bank obtained the 91-day treasury-bill return rate and used it to proxy the risk-free rate. Since the 91-day treasury bill was reported as an annualised return, it was geometrically divided into daily returns. The J203T was obtained from Bloomberg and used to represent the benchmark market return.

The discount rate of South Africa was used to identify the monetary environment, which was also obtained from the South Africa Reserve Bank. The repurchase rate in South Africa was used as a proxy of the discount rate. The reason for using the discount rate as the indicator of policy stringency is based on the findings of Bernanke and Blinder (1988) that several studies model the influence of monetary policy on financial market participants through the impact on bank lending rate or the availability of money. Discount rates define returns on cash savings, and investors in shares are bound to expect returns on risky portfolios to exceed interest rates on savings.

\section{The construction of SMB and HML portfolios}

Fama and French (1996) found evidence suggesting that the three-factor model captures the economic essence of losers and winners. Furthermore, they contended that losers load more heavily on the small minus big (SMB) and high minus low (HML) portfolios. Based on this finding, it is important to test whether South Africa has the same phenomenon. The following are the details of the process of building SMB and HML portfolios:

$$
\begin{aligned}
& S M B=\frac{\left[\left(+\frac{S}{M}+\frac{S}{H}\right)-\left(\frac{B}{L}+\frac{B}{M}+\frac{B}{H}\right)\right]}{3} \\
& H M L=\frac{\left[\left(\frac{S}{H}+\frac{B}{H}\right)-\left(\frac{S}{L}+\frac{B}{L}\right)\right]}{2}
\end{aligned}
$$

Firstly, all the shares were divided into two groups (big and small size) by comparing each share to the median. If the market value of shares was more significant than the median, they were placed into the big size group. If the market value of shares was smaller than the median, they were put into the small size group. The reason for choosing the median instead of the mean is that the market value of the JSE Top 40 takes up a large percentage of market capitalisation (over 90\%) in the total market value of the sample. Therefore, there were two groups for the shares' market value for each period, big and small. Furthermore, all the shares were separately divided into three groups (high, medium, and low) according to their price-earnings ratio $(\mathrm{P} / \mathrm{E})$ ratios. For each period, all the shares' $\mathrm{P} / \mathrm{E}$ ratios were compared within each group, then further divided into the following three groups: High P/E (top 30\%) group, medium $\mathrm{P} / \mathrm{E}$ (middle hierarchy from $30 \%-70 \%$ ) group, and low $\mathrm{P} / \mathrm{E}$ (bottom $30 \%$ ) group. The holding period for both portfolios was from the year ' $t$ ' to year ' $t+1$ ', and all shares were divided into these six groups: $B / L$, 
$\mathrm{B} / \mathrm{M}, \mathrm{B} / \mathrm{H}, \mathrm{S} / \mathrm{L}, \mathrm{S} / \mathrm{M}, \mathrm{S} / \mathrm{H}$, which are the groups based on their prior market value and $\mathrm{P} / \mathrm{E}$ ratio during the lookback period from year $\mathrm{t}-1$ to year $\mathrm{t}$. The equal-weighted return rate of these six groups was calculated in each trading month and strung together to form the portfolio returns from 2005 to 2019 (totalling 169 months, which is the same as the following LMW portfolios).

The total amount of monthly returns used in the sample was 77402 , and this was calculated by multiplying the 169-month sample period by 458 firms. Table 1 shows the available numbers of each group. The evolution of the R1 invested in different equity securities' portfolios is depicted in Figure 3. Figure 4 depicts the evolution of the R1 invested in J203T (market benchmark), 91-days bills (risk-free) and market risk premium.

Table 1: Available numbers for each group

\begin{tabular}{|c|c|c|c|c|c|}
\hline $\mathrm{B} / \mathrm{H}$ & $\mathrm{B} / \mathrm{M}$ & $\mathrm{B} / \mathrm{L}$ & $\mathrm{S} / \mathrm{H}$ & $\mathrm{S} / \mathrm{M}$ & $\mathrm{S} / \mathrm{L}$ \\
\hline 4678 & 4464 & 3880 & 2542 & 2924 & 5839 \\
\hline
\end{tabular}

Figure 3: The evolution of the R1 invested in HML, LMW, SMB, market risk premium portfolios under restrictive and expansive monetary conditions

The evolution of the R1 invested in 4 different portfolios

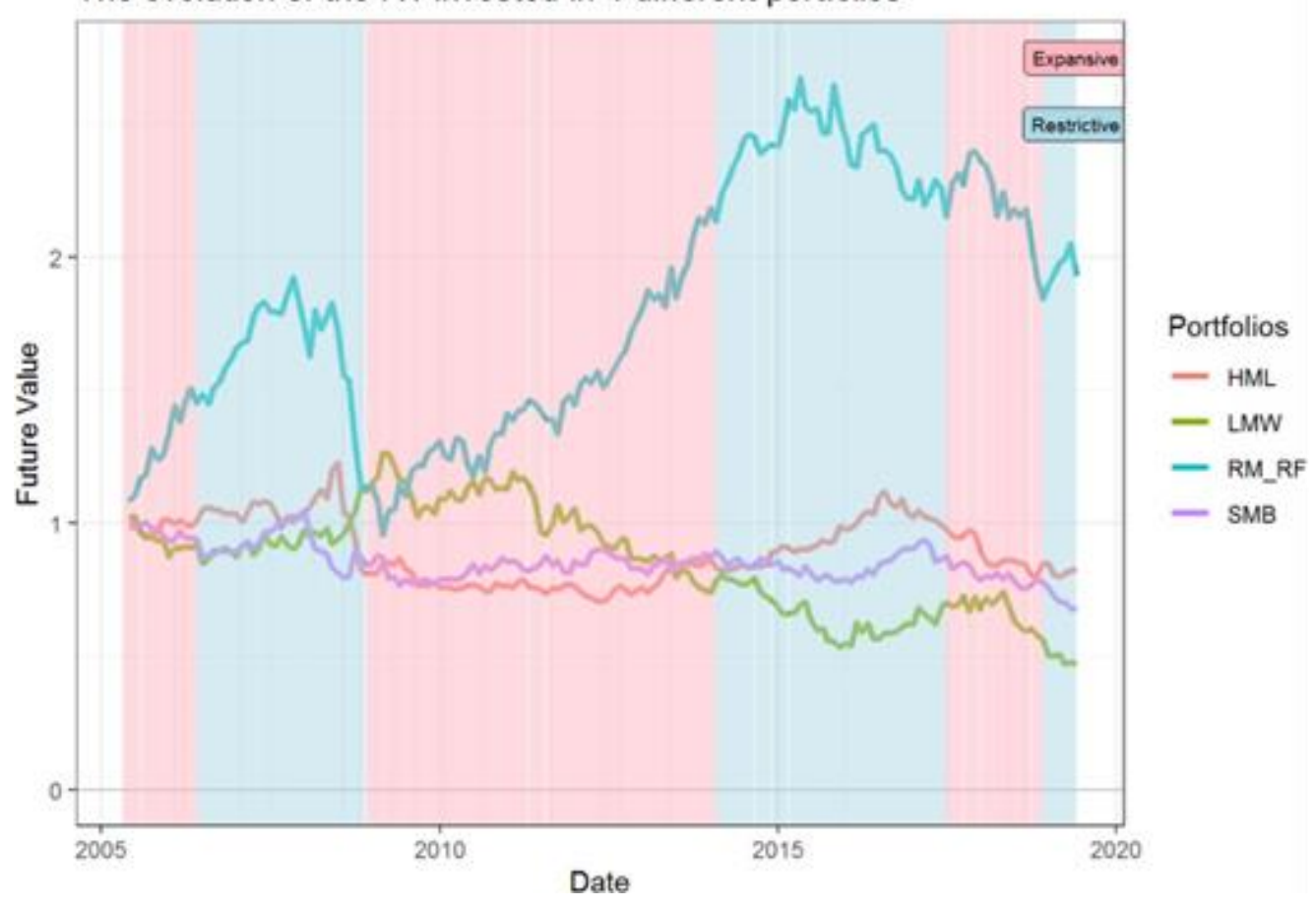


Figure 4: The evolution of the R1 invested in J203T (market benchmark), 91-days bills (risk-free) and market risk premium.

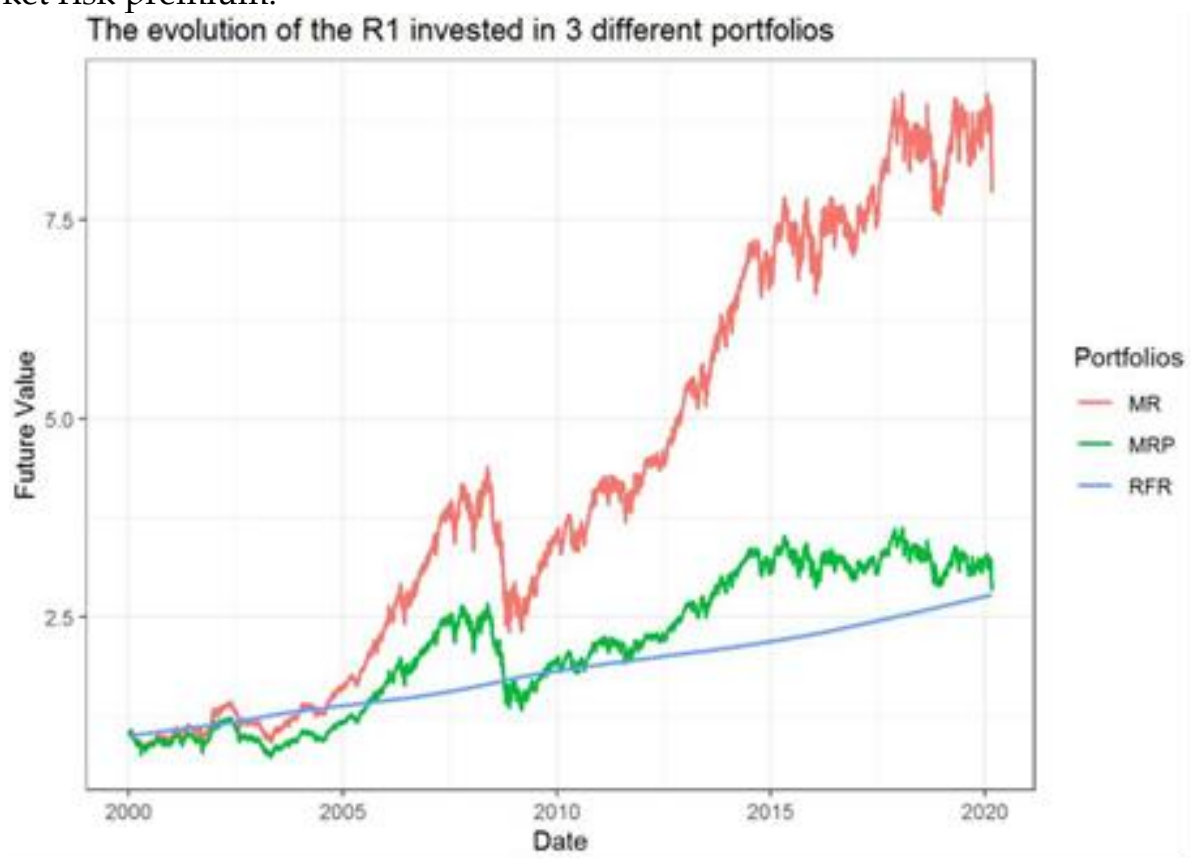

\section{Meaning and delimiting winning and losing portfolio}

The report started by looking at sample shares from a specified date and defining this date as the portfolio-formation date $(t=0)$. The cumulative excess returns for the prior 60 months to the last 13 months (the portfolio-formation period) will then be presented. The selection of the portfolio-formation period is in line with the findings reported in Fama and French (1996). They determined that the most significant long-term reversal exists when the formation period is based on share returns from month -60 through month -13 relative to the evaluation period, a five-year lookback period, except for a one-year skip period. This allowed us to separate the influence of short-term price momentum from the long-run reversal effect. For example, the lookback period of the first performance interval starts from 2000 to 2003 (four years). The holding period was the whole year of 2005, and the data of 2004 were excluded to avoid the potential influence of short-term price momentum. The cumulative excess returns were ranked from low to high.

Firms in the top $20 \%$ were assigned to the winner portfolio, and the firms in the bottom $20 \%$ were given to the loser portfolio, which is consistent with Garcia-Feijoo and Jensen (2014). After defining all the loser and winner groups from 2005 to 2019 (total 169 months), the next step was to calculate the return rate of the LMW portfolio. The grouping of each holding period was based on the previous performance through a four-year formation period. The equal-weighted monthly return was quickly figured out by simply using the losers' portfolio minus the winners' portfolio. Finally, they were strung together to form the LMW portfolio's monthly returns from 2005 to 2019 (169 months).

\section{Meaning of the monetary condition}

The repurchase rate was used as the proxy of the discount rate in South Africa. The changes in discount rates were viewed as the shifts in the South African broad monetary policy. For the periods when the discount rate increased, we argued that this period is restrictive where the general approach is constraining. For the periods where the discount rate decreased, we assumed that this period is expansive, and that the broad policy is unrestrictive. We defined the monetary environment as restrictive if the discount rate signalled constraining conditions where the discount rate was increasing. Furthermore, we classified an expansive environment when the discount rate was decreasing. For example, conditions are expansive when the discount rate is decreasing from month $t-1$ to month $t$. There was a sharp shift before 
and after the financial crisis in 2008. Furthermore, monetary conditions were considered maintained for these months in which the discount rate was unchanged.

Figure 5: The movement of repo rate in South African from 2005 to 2019 (14 years) and the restrictive and expansive monetary conditions during this period

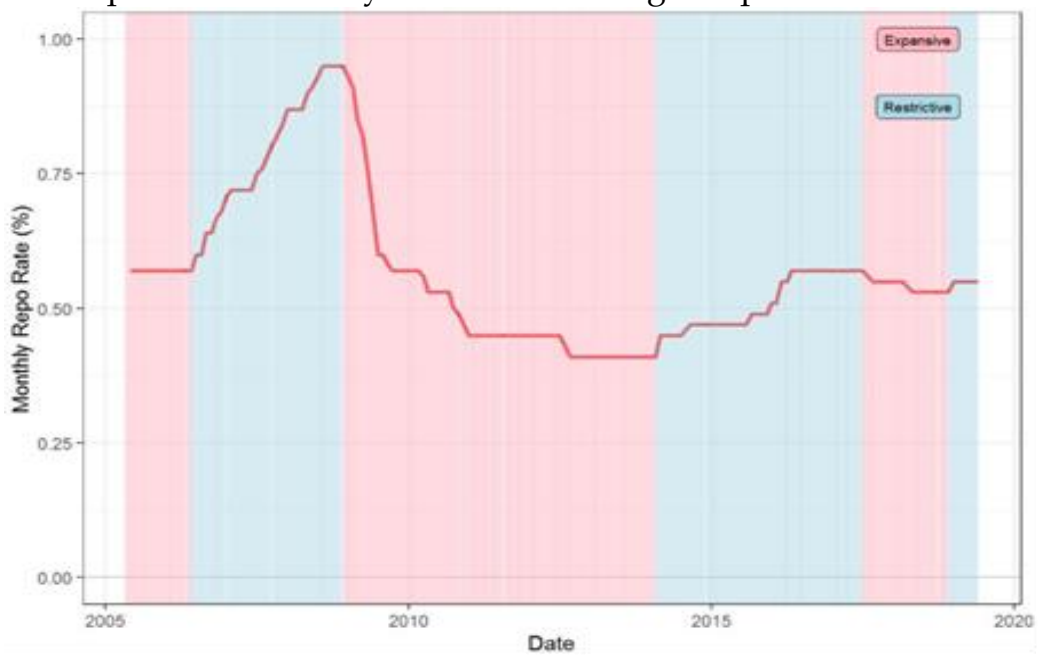

The exploration of the analytical framework

Fama-French three-factor with January Dummy model

The Fama and French three-factor model was used because Fama and French (1996) found evidence suggesting that the three-factor model captures the economic essence of losers and winners. Specifically, they contended that losers behave similarly to small, distressed shares, and thus, losers load more heavily on the SMB and HML factors. In addition, scholars "produced evidence indicating that the LMW premium is strongly influenced by returns in January" (Garcia-Feijoo \& Jensen, 2014, p. 12). In Fama and French's (1996) three-factor regression model, the SMB and HML risk factors were constructed by forming portfolios that are rebalanced monthly.

The portfolios were built based on the past cumulative excess returns, and then an investigation of the relation between reversal returns and the Fama-French three factors can occur. This was done while considering the January effect. The influence of January has been proved in many studies (Anjum, 2020). Consequently, it was viable to see whether it is relevant in the context of South Africa. The following equation was used to determine the January effect:

$R_{i}-R_{f}=a_{i}+b_{i}\left(R_{m}-R_{f}\right)+s_{i} S M B+h_{i} H M L+j_{i}($ January Dummy $)+e_{i}$

Where $\mathrm{RM}-\mathrm{Rf}=$ the excess return on a broad market portfolio.

$\mathrm{SMB}=$ the difference between the return on a portfolio of small stocks and the return on a portfolio of large stocks

$\mathrm{HML}=$ the difference between the return on a portfolio of high-carrying amount-to-market equities and the return on a portfolio of low-carrying amount-to-market equities

$\mathrm{b}_{\mathrm{i}}, \mathrm{s}_{\mathrm{i}}$, and $\mathrm{h}_{\mathrm{i}}=$ the slopes in the regression model

\section{Fama-MacBeth model}

In this cross-sectional study section, the Fama-MacBeth model was used to test the relation between the return of loser (and winner) portfolios and the reversal returns. Furthermore, the findings were separated into the different monetary conditions and excluded or included the January influence, as mentioned above. This empirical study was divided into two steps based on the Fama-MacBeth regression method. Firstly, the cross-sectional regression was used to obtain the alphas and betas at each time ' $t$ ', and then we calculated the time-series average of these three coefficients. Here, the factor is the dummy variable of winner's and loser's portfolios. In the traditional cross-sectional regression, the above processes were done at once. However, in the Fama-MacBeth method, the time-series average of corresponding 
coefficients represents the coefficient estimate. Secondly, the one-sample t-test model was used on each coefficient (alpha, loser's, and winner's beta) to test whether the true mean of each coefficient was statistically significantly different to zero:

$$
\text { Rit }=\beta 0, t+\beta 1, t \text { Loser }, i+\beta 2, t \text { Winner, } i+e, i t
$$

\section{Results of analysis and discussion The evidence of reversals}

First, before examining the monetary policy effects of share reversals, it is imperative to determine whether reversals were present in the JSE over the 14-year sample period. Table 2 reports the equally weighted average returns for past performance in quintiles. Similarly, to Garcia-Feijoo and Jensen (2014), firms were allocated into quintiles (five groups) based on continuously compounded returns during the portfolio-formation period. The methodology states that the lowest past performance quintile was denoted as the loser portfolio, while the highest past performance quintile was marked as the winner portfolio.

Following Garcia-Feijoo and Jensen (2014) and Fama and French (1996), the portfolio return was measured from the month ' $t$ '. This month was determined to be 12 months after the -60 to -13 formation period. This was done to separate the momentum effect from the effect of long-run reversals. An additional reason for the -60 to -13 formation period is one of our primary objectives, namely, to determine whether monetary conditions explain the long-run reversal phenomenon.

Table 2 shows the mean monthly returns regression results of portfolios from May 2005 to May 2019. The losers failed, as it can be seen in Table 2, to outperform the winners' portfolio by 34 basis points. This means that firms with historically good performance have consistently been producing superior returns to firms with historic lousy performance. This observation contrasts the findings of Page and Way (1992) and Britten et al. (2016), who acknowledged the presence of long-run reversals. The finding shows the influence of institutional investors. These outcomes could be due to differences in time frames and external political and economic influences. In addition, Page and Way (1992) used a different metric to determine long-run reversals. The authors used a three-year formation period for their regressions, resulting in a $20 \%$ outperformance of LMW portfolios. Britten et al. (2016) used a different time horizon: Their examined period ranged from 1 January 1998 to 30 June 2013, whereas the time horizon of this study ranged from 2005 to 2019. This suggests that the differences in results could be due to differences in the periods examined.

Table 2: Mean monthly returns and regression results for past performance portfolios in the JSE: May 2005 to May 2019

\begin{tabular}{|c|c|c|c|c|c|c|}
\hline \multicolumn{7}{|c|}{ Reversal Portfolio } \\
\hline & Loser & P2 & P3 & P4 & Winner & LMW \\
\hline \multicolumn{7}{|c|}{ Panel A. Mean Monthly Return for Past-Performance Portfolios } \\
\hline Mean return & -0.10 & 0.35 & 0.21 & 0.34 & 0.24 & -0.34 \\
\hline t-statistic & -0.28 & 1.16 & 0.68 & 1.13 & 0.72 & -1.01 \\
\hline \multicolumn{7}{|c|}{ Panle B. Regression Results for Explaining Past-Performance Portfolio Returns } \\
\hline a & $-1.17^{* * *}$ & $-0.54 * * *$ & $-0.72^{* * * *}$ & $-0.61^{\text {**** }}$ & $-0.76^{* * * *}$ & $-1.05^{* * * * *}$ \\
\hline b & $0.87^{* \omega *}$ & $0.86^{* * *}$ & $0.86^{* * *}$ & $0.82^{\text {*क* }}$ & $0.94^{* * *}$ & -0.05 \\
\hline s & $0.90^{* * *}$ & $0.56^{* * *}$ & $0.59^{* * *}$ & $0.58 * * *$ & $0.52 * * *$ & $0.39^{* * * *}$ \\
\hline $\mathrm{h}$ & -0.08 & -0.06 & $-0.12^{*}$ & -0.05 & -0.01 & -0.04 \\
\hline j & $2.08^{* *}$ & -0.76 & -0.23 & 0.29 & 0.05 & 2.06 \\
\hline t(a) & -4.06 & -2.97 & -3.45 & -3.10 & -3.68 & -3.09 \\
\hline t(b) & 11.73 & 18.35 & 16.07 & 16.07 & 17.77 & -0.64 \\
\hline$t(s)$ & 8.22 & 7.96 & 7.38 & 7.70 & 6.67 & 3.51 \\
\hline $\mathrm{t}(\mathrm{h})$ & -0.80 & -0.91 & -1.81 & -0.88 & -0.19 & -0.41 \\
\hline$t(j)$ & 2.08 & -1.20 & -0.32 & 0.42 & 0.08 & 1.74 \\
\hline $\mathrm{R}^{\wedge} 2$ & 0.46 & 0.67 & 0.60 & 0.61 & 0.66 & 0.10 \\
\hline
\end{tabular}


Note: Panel A shows equally weighted average monthly returns (in \%) for portfolios. They are divided into quintiles based on past performance. Following Fama and French (1996), portfolios are formed based on returns between months -60 and -13 relative to measurement month $t$. Panel $B$ reports regressions of monthly excess returns for past performance portfolios on the Fama-French three factors. The three factors and dummy variable (January) is calculated as follows:

$R i-R f=a i+b i(R m-R f)+\operatorname{siSMB}+h i H M L+j i($ January Dummy $)+e i$

The final column presents results for the LMW in the JSE.

***Significant at the $1 \%$ level

**Significant at the $5 \%$ level

Garcia-Feijoo and Jensen's (2014) US study acknowledged the presence of long-run reversals. Their study saw the losers outperforming their winner counterparts by 90 basis points between 1963 and 2010 . As stated in the literature review, their study was a 17-year extension of Fama, and French's (1996) study and their results corresponded well. Fama and French (1996) discovered a 74-basis point gap between the losers and winners.

In Panel B in Table 2, it is worth noting that the coefficients of the market risk premium and SMB factor are all positive and are statistically significant at the $1 \%$ level. This means that the market risk premium and SMB factor positively influence excess return based on their different quintiles. The HML factor coefficient is negative and is way smaller than the above two factor exposures. The HML factor has a slightly negative influence on the excess return, and this influence is statistically insignificant. Based on these findings, we can argue that the SMB and market risk premium factor could capture the excess return in the different quintiles. According to Fama and French (1996), the three-factor model captures the economic essence of losers and winners, and these factors are the market risk premium (Rm-Rf), SMB and HML. The authors claimed that losers behave similarly to small, distressed stocks; therefore, losers carry more weight on the SMB and HML factors of the three-factor equation.

In addition, De Bondt and Thaler (1987) and Grinblatt and Moskowitz (2004) found that January returns strongly influence the LMW premium; hence, we investigated the relationship between reversal returns and Fama and French's (1996) three factors with January effects in mind. To determine the impact of January on the loser, winner and LMW portfolios, January was later factored out of the equation to determine if January has a significant, overweight effect on the regression results. As shown in Panel B in Table 2, the coefficient of the January dummy factor is only statistically significant at $5 \%$ in the excess return of the loser portfolio, and this coefficient is positive. In other words, the January effect has a strong influence on the loser portfolio. The relationship between the January effect and the excess return of the loser portfolio is positive. This finding is also confirmed by De Bondt and Thaler (1987) and Grinblatt and Moskowitz (2004), which is explained in detail in Table 3. The adjusted R-square is relatively high in our regression model, with an average of 0.6 , excluding the regression on the LMW portfolio. In other words, the regression model that we used fitted well.

\section{The January effects}

January has a history of producing superior returns in securities. As stated in the literature review, De Bondt and Thaler (1987) and Grinblatt and Moskowitz (2004) reported that long-run reversals hold significant weight in results in January. George and Hwang (2007) further confirmed this theory by stating that long-run reversals of loser stocks are significantly exclusive to January. Muller (1999) acknowledged the presence of overreaction in South Africa to a point where he needed to factor out January from his empirical research to determine the effect of the month on long-run reversals. The empirical results, shown in Table 3 opposes previous findings and exhibits a consistent presence of loser reversals. In Table 3 , Panel A, where the whole year, including January, is included, and Panel B, where January is factored out of the equation, shows whether January did indeed have a significant effect on the outcomes 
Table 3: Long-run reversals and January returns in the JSE

\begin{tabular}{|c|c|c|c|}
\hline & $\beta 0$ & Loser & Winner \\
\hline \multicolumn{4}{|c|}{ Panel A. Full sample } \\
\hline Coefficient & -0.3412 & $-0.4027^{*}$ & -0.0587 \\
\hline t-statistic & -1.1899 & -1.4680 & -0.3083 \\
\hline \multicolumn{4}{|c|}{ Panel B. January Excluded } \\
\hline Coefficient & -0.2752 & $-0.5865^{* *}$ & -0.0741 \\
\hline t-statistic & -0.9653 & -2.0989 & -0.3707 \\
\hline
\end{tabular}

Note: The table shows the results of monthly Fama-MacBeth (1973) regressions of the form:

Rit $=\beta 0, t+\beta 1, t$ Loser $, i+\beta 2, t$ Winner $, i+e, i t$

The Rit is the return to stock $i$ in month $t$. Loser (winner) is a dummy variable that takes the value of 1 if stock $i$ is in the lowest (highest) quintile based on their continuously compounded returns from month -60 through the month -13. At the top of Table 3, loser and winner mean the corresponding coefficient estimates, calculated by the timeseries average, in \%. The portfolio-formation period of our samples is from May 2005 through May 2019 (169 months).

**Significant at the $5 \%$ level

* Significant at the $10 \%$ level

In Table 3, Panel A shows that the loser reversals failed to rebound with a 40,27-basis point drop in returns. Panel B shows that the losers experienced a further reduction of 58,65 basis points, excluding January. This 18,33-basis points difference confirmed our findings in Table 2, showing that the January effect has a substantial significant influence on the loser portfolio. Garcia-Feijoo and Jensen's (2014) January effect results were consistent with De Bondt and Thaler's (1987) and George and Hwang's (2007) theories. Their results confirmed a strong existence of long-run reversals over their 571-month sample period. The returns for losers generally rebounded by 59 basis points but dropped remarkably to 15 basis points after factoring out January, while winner reversals experienced a 31-basis point drop. As shown in the last column in Table 3, the winner portfolio also failed to yield a reversal with negative coefficients of $-5,87$ basis points and $-7,41$ basis points. However, these results were also shown to be statistically insignificant. Based on those findings, this finding is the same as in Table 2 in which we found that the mean monthly return of the LMW portfolio is $-0,34 \%$, which means that the winner portfolio keeps performing better than the loser portfolio. In other words, the long-run reversal of loser and winner does not exist in South Africa, while the January effect does affect the loser portfolio return.

The monetary environment and long-run reversal

Table 4: LMW returns, under expansive and restrictive monetary environments

\begin{tabular}{lccc}
\hline & Expansive ( $\mathrm{n}=\mathbf{9 2})$ & Restrictive ( $\mathrm{n}=\mathbf{7 7})$ & T-statistical \\
\hline LMW portfolio return & $-0.6252 \%$ & $-0.0080 \%$ & 0.9003 \\
\hline
\end{tabular}

Note: Table 4 displays average monthly returns for the LMW portfolio in expansive and restrictive monetary periods. Following Fama and French (1996), loser and winner portfolios were determined based on continuously compounded returns between months ranging between -60 and -13 , relative to the portfolio-formation period month $t$. The sample portfolio-formation period is from May 2005 to May 2019 (169 months).

We ran the two-sample t-test to examine whether the mean of the LMW was significantly different under both monetary conditions. Table 4 shows the LMW returns during both the expansive period and restrictive monetary environments. It can be seen that the loser reversals were not as evident, with the mean monthly return of the LMW portfolio showing a $-62,52$ basis point balance during the expansive period and a $-0,70$ basis point during the restrictive period. This slight increase in the latter period may suggest that a reduction of liquidity and money supply encourages individuals to invest more in loser portfolios, which gradually increases their share returns. Figure 6 supports Table 4's findings of a constant underperformance with the loser line of monthly returns consistently falling below the winner line for the most part, except at the beginning of the financial crisis where the South African Reserve Bank 
implemented an expansive monetary policy that boosted the loser portfolio over that duration. Furthermore, the LMW portfolio line exhibited a spike at the beginning of the 2008 global financial crisis but then started to experience a decline.

The LMW returns discovered by Garcia-Feijoo and Jensen (2014) were at 1,85\% during the expansive period. However, during the restrictive period, it was less than half the size at $0,48 \%$. Based on those findings, they argued that monetary conditions strongly influence the long-run reversals. In other words, there was a solid long-run reversal in share prices when the conditions were expansive in the US markets during their 571-sample month period. On the contrary, when the economic environment was restrictive, the mean reversal findings were significantly diminished.

Figure 6: The evolution of the R1 invested in loser, winner and LMW portfolios

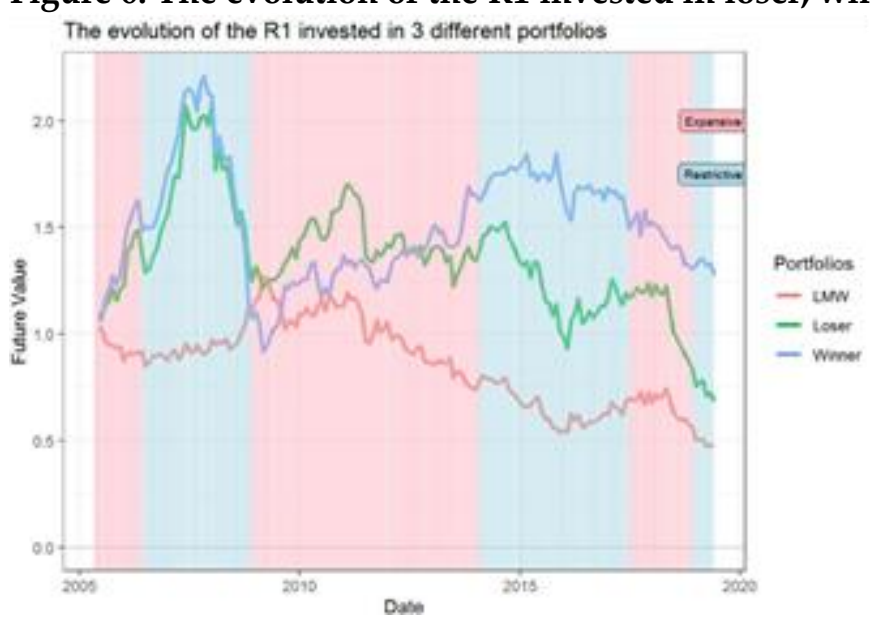

Table 5 builds on Table 3 by looking at the effects of the monetary environment on the long-run reversals of the JSE listed firms. Table 3 only determined whether reversals were present over the sample period, but Table 5 shows how the results differ when taking South Africa's monetary environment into account. The empirical study separated the Fama-MacBeth regression results into the two types of monetary environments, namely expansive and restrictive.

Table 5: Long-run reversals under both monetary environments in the JSE

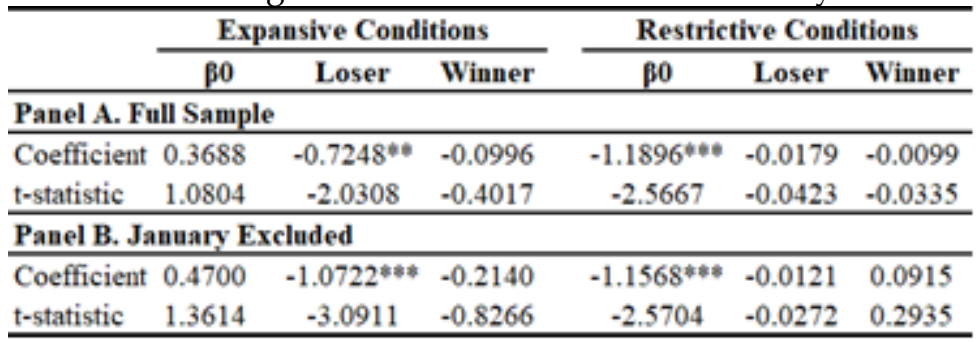

Note: The table shows the results of monthly Fama-MacBeth (1973) regressions. The formula is presented as follows: Rit $=\beta 0, t+\beta 1, t$ Loser $, i+\beta 2, t$ Winner $, i+e, i t$

Where Rit is the monthly stock return $i$ in month $t$, and loser (winner) is a dummy variable that takes the value of 1 if the stock is in the lowest or highest quintile based on continuously compounded returns over months ranging between -60 and -13 . The monetary environment is determined based on monetary policy variables, in which the repo rate of South Africa was used as the indicator. Loser and winner represent the corresponding (time-series average) coefficient estimates in the table in \%. The sample portfolio-formation period is from May 2005 to May 2019 (169 months).

***Significant at the $1 \%$ level

**Significant at the 5\% level

Table 5 shows that when classifying reversals under the two monetary environments, the losers perform significantly worse under expansive conditions than restrictive conditions. Under expansive monetary conditions, the losers exhibited a 72,48-basis point drop in mean monthly returns but 
interestingly improved to a $-1,79$ basis point change under restrictive conditions. The loser results in expansive conditions were significant at the $5 \%$ level. This is counterintuitive to Garcia-Feijoo and Jensen's (2014) US study who showed that losers significantly outperform winners under expansive conditions. Garcia-Feijoo and Jensen's (2014) study opposed these findings with an observed positive 1,51\% loser reversal when the monetary environment was expansive but a drop in mean monthly returns to $0,18 \%$ when the monetary environment was restrictive.

In Table 5, Panel B excludes January to determine the difference in results when the power of the January effect is taken out of account. Under expansive conditions, the loser shares failed to experience reversals with a 107,22 basis points drop at a 1\% significance level. They performed worse when January was factored out. This supports theories by De Bondt and Thaler (1987) that January has a more positive effect on January returns. During the restrictive conditions, the losers did improve significantly to a $-1,21$ basis point level. The winners still managed to produce better mean monthly returns during both monetary environments. The winners did experience poor performance during the expansive conditions but still managed to perform better than their loser counterparts. During the restrictive monetary conditions, the sample winners managed to generate positive returns at 9,15 basis points. In comparison, Garcia-Feijoo and Jensen (2014) found that winners' change in a mean monthly reversal in the US was negligible with a $-0,37 \%$ reversal during the expansive conditions and a $-0,30 \%$ mean monthly reversal during restrictive conditions. Excluding January in their study did show a significant drop in loser reversals from a $1,51 \%$ loser reversal in expansive conditions to $0,76 \%$ in the same environment. This confirms De Bondt and Thaler's (1987) and Grinblatt and Moskowitz's (2004) theory that long-run reversals for losers are more concentrated in January.

\section{Conclusion}

This research looked at the relationship between South Africa's monetary policy and the reversal returns of JSE listed firms. Long-run stock reversals are when firms with poor share performance over the long run (five years) eventually outperform companies with good share performance. The research aimed to determine whether differing monetary policy environments (expansive and restrictive) influence the reversals of the JSE listed firms in South Africa. An expansive monetary policy occurs when the South African Reserve Bank aims to stimulate economic growth by lowering short-term interest rates and expand the country's money supply. On the contrary, restrictive monetary policy occurs when the South African Reserve Bank aims to combat inflation by raising short-term interest rates and limit the money supply of South Africa. These two monetary environments had positive consequential effects in GarciaFeijoo and Jensen's (2014) US study where reversals did occur in the US markets and did exhibit significant changes in results among loser and winner portfolios. The losers in the US did outperform winners, especially during expansive conditions, but their outperformance was more limited during restrictive conditions. The South African adopted study failed to find loser firms beating winners in both expansive and restrictive monetary conditions, with losers continuously underperforming winners in the long run but closing the gap during restrictive conditions. This was counterintuitive to our hypothesis based on Garcia-Feijoo and Jensen's (2014) monetary findings and Page and Way's (1992) and Bitten et al.'s (2016) acknowledgement of reversal occurrence in South Africa. January positively affected the loser portfolio, where the losers did not perform as severely when January was included in the analysis. Once January was excluded, the losers performed a lot worse in comparison.

\section{Limitations and recommendations}

The limitation of the empirical research was that many firms did not have all the required data to do a complete sample analysis. The data was suggested to be converted daily; however, it was difficult to restructure the approach because of time constraints. It is acknowledged and understood that 42250 data points are significantly more than 169 data points and may have brought more conclusive results. However, the daily time-series data of market risk premium did yield a similar curve to our monthly time series. The holding period of the LMW portfolio was one year, which was inspired by Garcia-Feijoo and Jensen (2014). However, the results did not find long-run reversal patterns in the sample. Therefore, it is 
probable that this kind of reversal will show up if one expands the holding period. It is recommended that a more in-depth analysis of firm-specific factor effects in South Africa could help develop research in the field of monetary policy and price reversals. We also recommend that future research considers the tax and clientele effects on share price reversal.

The authors' substantive contribution(s) to the current conference article are in the table below.

\begin{tabular}{|c|c|c|c|c|c|c|c|c|}
\hline Author name & 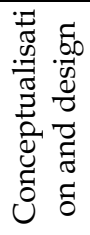 & 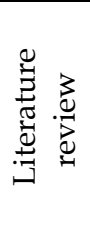 & $\begin{array}{l}\tilde{0} \\
\stackrel{0}{0} \\
\stackrel{0}{0} \\
0 \\
0 \\
\frac{\pi}{0} \\
0\end{array}$ & 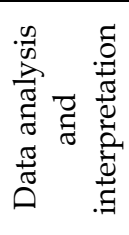 & 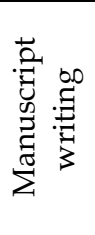 & 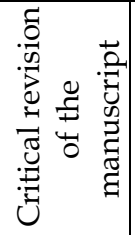 & 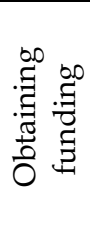 & 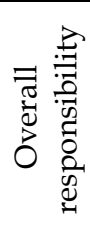 \\
\hline Rollins NG Ayaya & $X$ & $X$ & $X$ & $X$ & $X$ & & & $X$ \\
\hline Runxin Lin & $X$ & $\bar{X}$ & $x$ & 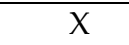 & & & & \\
\hline Onesmus Ayaya & & $X$ & & & $X$ & $X$ & $X$ & \\
\hline
\end{tabular}

\section{References}

Anjum, S. (2020). Impact of market anomalies on the stock exchange: A comparative study of KSE and PSX. Future Business Journal, 6(1), 1-11.

Arendas, P., Chovancova, B., Kotlebova, J., \& Koren, M. (2021). January anomalies on CEE stock markets. Investment Management and Financial Innovations, 18(4), 120-130.

Ayaya, O. (2002). Financial liberalisation, savings and investments: Evidence from a cointegration examination (Part 1). South African Association of Accountants Biennial International Conference Proceedings, June 26-28, 2002, Port Elizabeth (pp. 385-401).

Bekaert, G., \& Hodrick, R. J. (1992). Characterizing predictable components in excess returns on equity and foreign exchange markets. The Journal of Finance, 47(2), 467-509.

Bernanke, B. S., \& Blinder, A. S. (1988). Credit, money, and aggregate demand (No. w2534). National Bureau of Economic Research.

Britten, J., Auret, C., \& Page, D. (2016). Investigating the interaction between long-term reversal and value on the JSE. Studies in Economics and Econometrics, 40(2), 1-24

Bjørnland, H. C., \& Leitemo, K. (2009). Identifying the interdependence between US monetary policy and the stock market. Journal of Monetary Economics, 56(2), 275-282.

Blackburn, D. W., \& Cakici, N. (2017). Overreaction and the cross-section of returns: International evidence. Journal of Empirical Finance, 42, 1-14. https://doi.org/10.1016/j.jempfin.2017.02.001

Chui, A. C., Subrahmanyam, A., \& Titman, S. (2021). Momentum, reversals, and investor clientele (No. w29453). National Bureau of Economic Research.

De Bondt, W. F., \& Thaler, R. H. (1985). Does the stock market overreact? The Journal of Finance, 40(3), 793-805.

De Bondt, W. F., \& Thaler, R. H. (1987). Further evidence on investor overreaction and stock market seasonality. The Journal of Finance, 42(3), 557-581.

Dyl, E. A., Yuksel, H. Z., \& Zaynutdinova, G. R. (2019). Price reversals and price continuations following large price movements. Journal of Business Research, 95, 1-12.

Fama, E. F., \& MacBeth, J. D. (1973). Risk, return, and equilibrium: Empirical tests. Journal of political economy, 81(3), 607-636.

Fama, E. \& French, K. (1992). The cross-section of expected stock returns. Journal of Finance, 47(2), 427-465.

Fama, E. F., \& French, K. R. (1996). Multifactor explanations of asset pricing anomalies. The Journal of Finance, 51(1), 55-84.

Fry, M., Julius, D., Mahadev, L., Roger, S., \& Gabriel, S. (2000). Key issues in the choice of the monetary policy framework. In L. Mahadeva \& G. Sterne (Eds.), Monetary Policy Frameworks in a Global Context. Routledge.

Garcia-Feijoo, L., \& Jensen, G. R. (2014). The monetary environment and long-run reversals in stock returns. Journal of Financial Research, 37(1), 3-26.

George, T. J., \& Hwang, C. Y. (2004). The 52-week high and momentum investing. The Journal of Finance, 59(5), 21452176.

George, T. J., \& Hwang, C. Y. (2007). Long-term return reversals: Overreaction or taxes? The Journal of Finance, 62(6), 2865-2896. 
Grinblatt, M., \& Moskowitz, T. J. (2004). Predicting stock price movements from past returns: The role of consistency and tax-loss selling. Journal of Financial Economics, 71(3), 541-579.

Hsieh, H. H., \& Hodnett, K. (2011). Tests of the overreaction hypothesis and the timing of mean reversals on the JSE Securities Exchange (JSE): The case of South Africa. Journal of Applied Finance E Banking, 1(1), 107-130.

Hong, H., \& Stein, J. (1999). A unified theory of underreaction, momentum trading and overreaction in asset markets. Journal of Finance, 54, 2143-2184.

Miranda-Agrippino, S., \& Rey, H. (2020). US monetary policy and the global financial cycle. The Review of Economic Studies, 87(6), 2754-2776

Muller, C. (1999). Investor overreaction on the Johannesburg Stock Exchange. Investment Analysts Journal, 28(49), 5-17. https:// doi.org/10.1080/10293523.1999.11082392

Page, D., Britten, J., \& Auret, C. J. (2013). Momentum and liquidity on the Johannesburg Stock Exchange. International Journal of Economics and Finance Studies, 5(1), 56-73.

Page, M. J., \& Way, C. V. (1992). Stock market over-reaction: The South African evidence. Investment Analysts Journal, 21(36), 35-49. https:/ / doi.org/10.1080/10293523.1992.11082314

Rif, A., \& Utz, S. (2021). Short-term stock price reversals after extreme downward price movements. The Quarterly Review of Economics and Finance, 81, 123-133.

Statista (2020, August 27). South African inflation rate from 1984 to 2021.

http://statista.com/statistics/370515/inflation-rate-in-south-africa/

Trade Economics (2020, August 27). South Africa interest rate. http://tradingeconomics.com/south-africa/interestrate\#:-:text=In \%20the \%20long- term $\% 2 \mathrm{C} \% 20$ the.according $\% 20$ to $\% 20$ our $\% 20$ econometric $\% 20$ models

US Federal Reserve (2020, August 15). Historical approaches to monetary policy.

http://federalreserve.gov/monetarypolicy/historical-approaches-to-monetary- policy.htm

Zaremba, A. (2016). Has the long-term reversal reversed? Evidence from country equity indices. Romanian Journal of Economic Forecasting, 19(1), 88-103. 